\begin{tabular}{|l|l|}
\hline $\begin{array}{l}\text { En el umbral de Leopoldo Zea. Alberto Zum Felde: dramatismo ontológico de la } \\
\text { conciencia y voluntad de ser en la incertidumbre de la entidad americana }\end{array}$ & Titulo \\
\hline Crespo Gaggiotti, Horacio - Autor/a; & Autor(es) \\
\hline $\begin{array}{l}\text { De Raíz Diversa. Revista Especializada en Estudios Latinoamericanos (Vol. } 2 \text { no. } 4 \\
\text { jul-dic 2015) }\end{array}$ & En: \\
\hline México D.F. & Lugar \\
\hline $\begin{array}{l}\text { Programa de Posgrado en Estudios Latinoamericanos, Universidad Nacional } \\
\text { Autónoma de México }\end{array}$ & Editorial/Editor \\
\hline 2015 & Fecha \\
\hline $\begin{array}{l}\text { Zum Felde, Alberto; Zea, Leopoldo; Intelectualidad; Colonialismo; Cultura; México; } \\
\text { América Latina; Uruguay; }\end{array}$ & Colección \\
\hline Artículo & Temas \\
\hline $\begin{array}{l}\text { "http://biblioteca.clacso.edu.ar/Mexico/ppel-unam/20160627024912/Horacio_Crespo._En_el_umbral_de_Leopoldo_Zea__Alberto_Zum_Fe } \\
\text { Ide-dramatismo_ontologico_de_la_conciencia_y_voluntad_de_ser_en_la_incertidumbre_de_la_entidad_americana.pdr" }\end{array}$ & URL \\
\hline $\begin{array}{l}\text { Reconocimiento-No Comercial-Sin Derivadas CC BY-NC-ND } \\
\text { http://creativecommons.org/licenses/by-nc-nd/2.0/deed.es }\end{array}$ & Licencia \\
\hline
\end{tabular}

\begin{tabular}{|c|}
\hline $\begin{array}{c}\text { Segui buscando en la Red de Bibliotecas Virtuales de CLACSO } \\
\text { http://biblioteca.clacso.edu.ar }\end{array}$ \\
Consejo Latinoamericano de Ciencias Sociales (CLACSO) \\
Conselho Latino-americano de Ciências Sociais (CLACSO) \\
Latin American Council of Social Sciences (CLACSO) \\
www.clacso.edu.ar \\
\end{tabular}

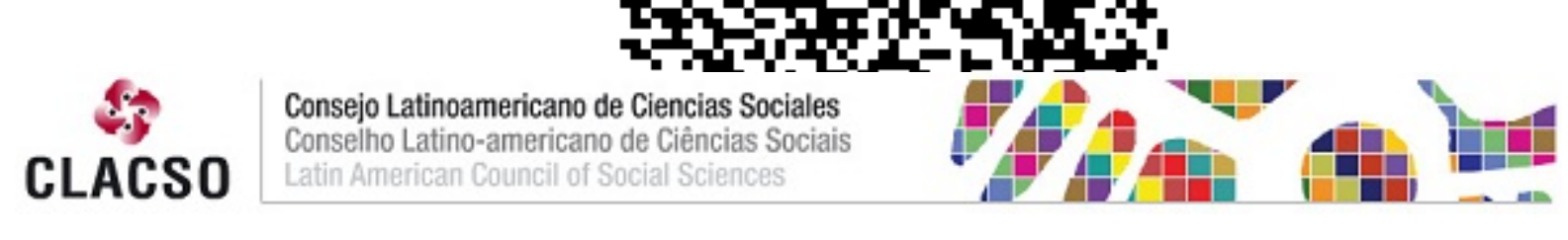




\title{
En el umbral de Leopoldo Zea. Alberto Zum Felde: dramatismo ontológico de la conciencia y voluntad de ser en la incertidumbre de la entidad americana
}

\author{
Horacio Crespo Gaggiottit ${ }^{*}$
}

RESUMEN: El autor propone una hipótesis de interpretación de la obra del filósofo Leopoldo Zea, la cual apuntaría a que se puede rastrear cierta afinidad entre algunas tesis desarrolladas por el maestro mexicano y aquellas que el intelectual uruguayo Alberto Zum Felde, planteó específicamente en su obra El problema de la cultura americana, publicada en 1943. Para ello, se nos ofrece un recorrido biográfico intelectual de Zum Felde y un análisis de los aspectos de mayor importancia que trata el libro, ya mencionado, concluyendo con una reflexión sobre el comentario que realizó Zea en la revista Cuadernos Americanos, señalando que desde ese momento surgió uno de los temas que trazaran la obra de Zea, la pregunta por América.

Palabras clave: Cultura americana, autenticidad, coloniaje intelectual, América, Zea.

Aвstract: The author proposes an interpretation of the work of the philosopher Leopoldo Zea which suggests that certain affinity can be traced between some theses developed by the Mexican master and those postulated by the Uruguayan intellectual Alberto Zum Felde, especially in his work called The Problem of the American Culture (El problema de la cultura americana) published in 1943. The author offers an intellectual biography of Zum Felde and an analysis of the most important aspects of the above mentioned book. The article is concluded with a reflection of the comment made by Zea in the journal Cuadernos Americanos in which the author notes that since then the problem of what is America turns into one of the principal themes that marked the work of Zea.

KEYWORDS: American culture, authenticity, intellectual coloniaje, America, Zea.

Recibido: 06 de mayo de 2015. ACEPtado: 20 de mayo de 2015.

\footnotetext{
Profesor Investigador de Tiempo Completo. Universidad Autónoma del Estado de Morelos <crespo.horacio@gmail.com>
} 
Si nuestra realidad, hoy, no es más que ésta -una interrogación, una inquietud, una angustia, una voluntad: la voluntad de ser, la angustia de no ser aún, la inquietud de nuestra perplejidad, la interrogación de nuestra búsqueda- sea ésta el imperativo de nuestra actitud y la verdad de nuestra expresión, en la literatura, en el arte, en la educación, en el gobierno. Este es ya un modo de la originalidad de ser, no siendo aún, porque es un modo de autenticidad; $y$ es, además, o ante todo, la actitud actualmente necesaria de nuestra realización en la Historia.

Alberto Zum Felde, El problema de la cultura americana, p. 97.

$\mathrm{E}$ cias", ni tampoco ejercer las herramientas de la nueva "historia intelectual" para lo cual faltaría conocer eventuales relaciones epistolares o contactos personales entre Leopoldo Zea y Alberto Zum Felde y disponer, además, de documentación que, en caso de existir, no está ahora a mi alcance. Lo que propongo es muchísimo más modesto: llamar la atención sobre la lectura por parte del filósofo mexicano de una obra notable del autor uruguayo, El problema de la cultura americana, construida sobre un conjunto orgánico de ensayos editados por Losada en Buenos Aires en diciembre de 1943, libro sobre el que ya pesa el olvido (Zum Felde, 1943). ${ }^{1}$ La certeza de la lectura realizada por Zea de este trabajo sustantivo del intelectual oriental no surge de una compulsa de textos o de una suposición un tanto azarosa fundada en una cábala conceptual más o menos verosímil, sino que tiene una base mucho más sólida: una reseña del libro publicada por Zea a fines del año siguiente en la por entonces novísima revista Cuadernos Americanos. Esta contribución en la revista del maestro Silva Herzog -forma de recepción no frecuente en Zea, y que en la modalidad de reseña aún lo es menos- atestigua el interés y reconocimiento del entonces joven estudioso mexicano por la indagación americanista, a todas luces original y de fuerte personalidad, del ya conocido profesor de Montevideo, del que además Zea citará en otras obras de este momento temprano, conceptos y desarrollos historiográficos muy significativos acerca de la cultura de su país, del que conviene no olvidar fue la patria de Rodó. $^{2}$

1 No deja de ser peculiar, en época de tantos "redescubrimientos" editoriales intrascencentes, que ninguna de las obras de Zum Felde haya sido reeditada recientemente, ni figure en los un tanto profusos corpus del latinoamericanismo.

2 De Rodó, sin embargo, Zum Felde tomará mucha distancia crítica, cf. la breve pero sustantiva aportación sobre Zum Felde en Real de Azúa (1964: 181-189). 
Los señalamientos que siguen persiguen recuperar -de allí las citas y glosas extensas- ese trabajo de Zum Felde, subrayando algunos elementos que me parecen muy sugerentes para la posterior obra de Zea: seguramente incitaciones, fórmulas, elaboraciones complejas que fueron de singular provecho en esa etapa germinal del pensamiento del maestro mexicano. Alejado este intento de toda pretensión filológica, en realidad éstas son notas para recrear un acuciante clima intelectual, del que Zum Felde no fue actor principalísimo pero sí una figura motivadora y sumamente atrayente, tanto en sus elaboraciones acabadas, como en sus tanteos, ambigüedades y aún, como él mismo dice, en ese avanzar contradictorio que es representado por su propio libro. La experiencia de la lectura del libro de Zum Felde es como sumergirnos en el "taller" original del que iría surgiendo precisamente, en la década venidera, el objeto de su búsqueda: el filosofar acerca de la entidad americana, cuyo protagonista central sería Leopoldo Zea.

\section{ALBERTO ZUM FELDE (1889-1976)3}

Este importante estudioso y ensayista que dejó su nombre asociado con la historia intelectual de Uruguay nació, sin embargo, en Argentina, más puntualmente en Bahía Blanca en 1889. Emilio Zum Felde, su padre, tenía ascendencia alemana; su madre, Josefina Alberdi, provenía de una antigua familia hispano-uruguaya; poco después del nacimiento de su hijo Alberto la pareja radicó en la banda oriental del Plata.

En el momento inicial de su trayectoria, el Novecientos montevideano estaba atravesado por la novedad estética y filosófica del modernismo, el impacto estruendoso de las innovaciones de Darío, la irrupción del anarquismo, la puesta en cuestión de las verdades teológicas por el positivismo y el sacudimiento radical provocado por los primeros atisbos, en estas tierras, de la obra de Nietzsche. Esta época -según Jorge Ruffinelli de un brillo irrepetible en la historia cultural y literaria de Montevideo- se fue expresando en la poesía de Julio Herrera y Reissig y de las infortunadas Delmira Agustini y María Eugenia Vaz Ferreira -ambas con finales lúgubres; de la primera José Carlos Mariátegui realizó una valoración

3 Las breves noticias biográficas y algunas referencias críticas de esta nota son deudoras de Exposición (1980), la entrada "Alberto Zum Felde", en Oreggioni (1987); Pickenhayn (1980), Real de Azúa(1964). 
emocionada y empática-, en la narrativa de Horacio Quiroga, Javier de Viana y Carlos Reyles, en el teatro de Florencio Sánchez, en la prosa y el pensamiento de José Enrique Rodó y Carlos Vaz Ferreira.

Desde muy joven, Zum Felde estrechó relaciones con los corrillos intelectuales de Montevideo, formando parte del círculo de Roberto de las Carreras, que se reunía en el pequeño Café Moka, en la calle Sarandí, estridente y con personalidad propia, diferenciado de los renombrados Tupí-Nambá, el Británico y, sobre todo, el legendario Polo Bamba, todos refugios de la intelectualidad bohemia de esos días. De esa experiencia, seguramente, es que Zum Felde pudo acuñar su definición certera de "intelectual de café" como un tipo cultural que en ese tiempo de novedades fue vehículo de un fresco cosmopolitismo, ajeno a las rancias estirpes del tradicionalismo y protagonista insoslayable de intercambios animados, reflexivos y creadores. Reflejos de los protagonistas de la modernidad iridiscente de París, Viena, Berlín, Budapest, Munich y, por supuesto, de la en ese momento espléndida Buenos Aires de Darío, Ingenieros, Lugones, Gálvez, Rojas. Sólo mucho más tarde, en los sesenta del pasado siglo, el concepto va a adquirir cierta connotación peyorativa (Michelena, 1986).

Este clima intelectual se personifica con contundencia en la figura del referente inicial de Zum Felde, Roberto de las Carreras -de quien dice Carlos Roxlo que "Todas las hadas asistieron a su bautizo; todas sin excepción, menos el hada de la Cordura" (Roxlo, 1916: VII, 52) - ${ }^{4}$ que en 1894 publicó Al lector, texto inaugural del modernismo uruguayo en la senda de Rubén Darío. De este desafiante dandy montevideano, una "estrella de primera magnitud en el cielo de la aldea: se consumió en un fogonazo" en la caracterización de Ángel Rama (Rama, 1967: 46), del que con penetrante sensibilidad histórica-literaria Jorge Ruffinelli precisa que "puede ponerse legítimamente en duda" que haya sido un escritor, pero del que -dibujando una figura paralela al inolvidable Charles de Soussens, compañero de la bohemia literaria de Darío en la vecina ciudad porteña- anota:

[...] consumió personalmente la posibilidad literaria, se convirtió él mismo en personaje, excéntrico, impar, increíble. La poesía y la prosa que ha dejado son exabruptos de una sensualidad exacerbada, propios del "libertino" que quería ser, y panfletos de feroz insolencia con los cuales

\footnotetext{
4 Sobre Roberto de las Carreras (1875-1963), cf. Rama (1967), Domínguez (1997). Un reconocimiento de Zum Felde de la importancia que tuvo De las Carreras en su temprana formación es que encabezó en Montevideo el entierro del poeta del decadentismo.
} 
buscó abofetear, tan sonoramente como fuera posible, a la aldea burguesa de Montevideo (Ruffinelli, 1974: 2).

El propio Zum Felde recuerda que usaba ropas vistosas - "jaquet gris y chalecos y corbatas fantásticas que había traído de París”-, paseando por las calles montevideanas, o instalándose en el Café Moka donde había constituido su cenáculo (Ruffinelli, 1974: 2). A partir de 1900, De las Carreras condujo junto con Herrera y Reissig importantes veladas literarias congregadas en el altillo de la residencia familiar del segundo en Montevideo, en las que se fue concretando definitivamente el abandono del neo-romanticismo en camino hacia la vanguardia modernista. ${ }^{5}$

Formado en esa capilla, en 1908 Zum Felde publicó sus primeros trabajos, varios con seudónimo, en El Eco del País, La Razón y en las revistas La Semana y Apolo de Montevideo y Caras y Caretas y Mundo Argentino en Buenos Aires. Sus influencias tempranas, de las que dejan marca, fueron Nietzsche -según declaró en su madurez, "su principal nutrición"- ${ }^{6}$ e Ibsen, y se hicieron visibles en el período de "Aurelio del Hebrón", seudónimo con el que firmó su primer libro, un conjunto de sonetos, Domus Aurea, aparecido en 1908, y dos piezas teatrales: Lulú Margat y La hiperbórea, publicadas ambas en la revista Apolo, editada por el poeta Manuel Pérez y Curis (1844-1920), en el mismo año. En la primera, una obra de tesis de marcado naturalismo, con tendencia al grotesco y alguna caída melodramática, el autor rechaza la hipocresía moral y la frivolidad burguesa y afirma la libertad femenina en la disponibilidad de su cuerpo, a tono con las más avanzadas concepciones europeas -Lou Andreas Salomé o Alma Mahler son referencias obligadas- pero en un anticipo notable, y a los ojos de la sociedad escandaloso, a los muy posteriores esfuerzos reivindicadores de género en el Plata (Zum Felde, 1908). Además, de este período es La ciega, obra escrita para la compañía de José Podestá, elenco que la estrenó al terminar la segunda década del siglo xx. La producción teatral de Zum Felde se completó en la década de 1930 con dos dramas metafísicos, Alción (1934) y Aula Magna o la Sibyla y el filósofo (1937).

\footnotetext{
5 Referido a Herrera y Reissig escribió Zum Felde, años después: “Sentimiento romántico, sensibilidad decadente, unidos, estilizados, destilados a través de los finísimos alambiques de su esteticismo formal, hacen de la poesía de Herrera una síntesis propia, una expresión auténtica en sí misma, y de las más valiosas, en la antología poética de esa gran época occidental de la Literatura; es decir, un clásico del modernismo" (Zum Felde, 1967: 216).

6 Declaración en El país, Montevideo, 26/8/1962, cit. por Real de Azúa , 1964.
} 
Tanto los sonetos como las piezas teatrales tempranas son típicamente modernistas y presentan con talento algunos rasgos sobresalientes de la literatura novecentista uruguaya. Posteriormente, Zum Felde renegó de los escritos juveniles de la etapa de Aurelio del Hebrón. ${ }^{7}$

Acontecimiento ejemplar de rebeldía juvenil novecentista, en el sepelio del poeta Herrera y Reissig el joven nietzscheano émulo de De las Carreras protagonizó un estridente episodio: pronunció sin invitación, en un alarde de desafío generacional, una alocución en el que imputó a la sociedad uruguaya, con virulencia verbal y cierta arbitrariedad, por algunas situaciones que habría vivido el poeta desaparecido. Algunos pasajes de este discurso inesperado son elocuentes muestras del lugar de elocución -el de impoluto portador de la verdad, fustigador de filisteos- que se asignaba el juvenil censor de la hipocresía burguesa:

¡Señores! Yo no he venido aquí a entonar loas ni a bordar bellas frases; no he venido a hacer simplemente literatura; he venido a lanzar una verdad que tengo en la conciencia, he venido a decir una verdad pura y sencilla como fue el alma del que yace. [...] Y la verdad es que vosotros todos, o casi todos los que rodeáis este cadáver fuistéis sus enemigos. Por vosotros sufrió, por vosotros le fue amarga la vida. Este que aquí reposa libre de las miserias de los hombres, fue siempre un paria entre vosotros. Y no creo que sea un sentimiento de amor lo que os trae a este acto, no creo que sea el hondo homenaje al poeta lo que inspira vuestras elegías hipócritas. Es quizá la vanidad patriótica que quiere reivindicar para sí, un nombre literario que no le pertenece, que no le pertenece porque no ha sabido conquistarlo. Muchos de los que estáis aquí, habéis venido sólo porque el muerto lleva un apellido distinguido y porque su familia es de abolengo en el país. [...] Sí, señores, sí; lo que yo quiero deciros sintetizando el espíritu de mi alocución, -que ha venido a turbar la armonía convencional de este acto, porque era necesario que así fuese, lo que quiero deciros de una vez por todas es que a pesar del homenaje sincero o no, que aquí estáis tributando, este cadáver no os pertenece (Zum Felde, 1910: s.p.).

\footnotetext{
7 "A más de sesenta años de publicados, don Alberto Zum Felde se horroriza de sus escritos juveniles, e, incluso, me ha acusado de traidor por haber descubierto y leído a Lulú Margat. Se niega obstinadamente a reconocer calidad en sus escritos juveniles. Estos escritos, no es preciso subrayarlo, no tienen ni la significación ni los valores de su labor posterior, y se hallan en una línea literaria que el autor abandonó después. Sin embargo, se ubican dentro de lo más saliente de la producción del grupo de los jóvenes novecentistas uruguayos, muestran algunas calidades evidentes y tienen una significación particular, ya que en cierto modo, prefiguran al escritor que Aurelio del Hebrón llegó a ser en su madurez" (Visca, 1971: s.p.).
} 
En 1917 Zum Felde publicó El Huanakauri, elaborado sobre el tema de una leyenda incaica acerca de la fundación de Cusco. El título está tomado del nombre del cerro en el que Manco Capac hundió su vara e hizo nacer el imperio, o sea está referido al mito del "lugar del origen", en un giro que marca sus futuras preocupaciones ontológicas sobre América. El autor se desprendía así de las ataduras del decadentismo, el modernismo y el naturalismo presentes en los sonetos de Domus Aurea y en el planteamiento de Lulú Margat. Este denso ensayo escrito en una intensa prosa poética, que revela en su composición el ascendiente de Walt Whitman y, por cierto, de Nietzsche sobre su autor, fue deliberadamente soslayado por la crítica. El texto parece constituirse en una proclama, cercana a muchos de los conceptos que un año más tarde estarían presentes en el célebre Manifiesto liminar de la Reforma Universitaria de Córdoba, con el que está vinculado por la percepción de la crisis civilizatoria europea provocada por la guerra y los mismos requerimientos e inquietudes generacionales de autonomía y búsqueda americana: "Queremos - ¡oh Pueblos-, pensar con nuestras cabezas, hablar con nuestra lengua, obrar con nuestro albedrío. Queremos ser nosotros mismos, no sombras ni reflejos de otros" (Zum Felde, 1917: 32). Un señalamiento resulta notable: "El Mito hará nuestra unidad, el Mito hará de nosotros un pueblo" (Zum Felde, 1917: 77). Esto último resulta sumamente sugerente y confirma lo anticipatorio que resulta el ensayista uruguayo en muchas de sus búsquedas y construcciones intelectuales ya que, unos cuantos años antes que Mariátegui, se refiere al poder del mito (de filiación nietzscheana y soreliana) como base inspiradora de la identidad americana, alejándose del racionalismo positivista de la anterior generación. Sobre el final de su trayectoria, en un extenso reportaje con Arturo Sergio Visca, el autor precisará:

El concepto universal básico [de El Huanakauri] es éste: que la cultura, que hasta entonces se tenía por algo postizo, como un traje de civilización intelectual, fue encarada por mí como una vivencia del ser. Esto es: para un americano intelectual, la autenticidad ontológica de su cultura depende de que la encare desde el punto de vista de América, asimilando la cultura universal, pero vivenciándola como americano; en caso contrario, sólo es exteriormente culto, postizamente culto (Visca, 1969: 37).

El elemento ontológico y la crítica a la inautenticidad de la cultura libresca, esencial de su libro de 1943 que nos ocupará más adelante, aparece tempranamente, lo que hace de El Huanakauri una pieza sugerente en la 
génesis del latinoamericanismo que se desarrollará con tanta intensidad después de la Segunda Guerra Mundial. La fuerza del mito incaico también estará presente en las elucubraciones de la generación de la reforma universitaria cordobesa, ya que una de las conferencias de la asociación “¡Córdoba libre!”, dictada por Arturo Capdevila, versaba sobre aspectos de la cultura de los Incas, tema al que el escritor cordobés luego dedicará un libro (Navarro Trujillo, 2009: 106-109).

En El Huanakauri Zum Felde proclama estentóreamente su fe en América, su creencia en un "americanismo radical", como instrumento de búsqueda de una auténtica autonomía espiritual americana, fundada a la vez en la tradición como en la realidad histórica contemporánea, que debe además adquirir para justificarse una proyección de validez universal.

Entre 1919 y 1929 se ocupó de trabajos de crítica literaria en el batallista diario El Día en su edición vespertina, que aparecía como El Ideal. Al final de la década de los veinte dirigió la renovadora y vanguardista revista La pluma, editada por Orsini M. Bertani, de la que se publicaron diecinueve números (de los cuales Zum Felde dirigió los primeros dieciséis, hasta su retiro forzado como ya veremos), entre agosto de 1927 y marzo de 1931 (El País cultural, 1997). En ambas actividades puso en práctica las teorizaciones de El Huanakauri; como crítico militante realizó una vigorosa revisión del pasado literario uruguayo y dirigió su atención a lo más interesante de la producción intelectual contemporánea, nacional y extranjera. Real de Azúa caracteriza su actividad crítica como de vigorosa renovación, aunque señala cierta tendenciosidad política por su militancia en el batllismo, que él vivía como un radicalismo populista:

[...] rompió con la dudosa tradición nacional, y aun sudamericana, de una crítica inhibida en su plena función por consideraciones de vanidad tradicional, por la inflación patriotera, política y localista, por vinculaciones familiares y de clase, por la piedad sentimental, por ambiciones descolocadas. [...] Desdeñó, aunque pese a su ejemplo siguieran viviendo, la crítica de cortesía y la del bombo mutuo, la crítica de glosa (como la muy buída de Rodó sobre Darío), la de resúmenes de obras y disgresión incontrolada, a la Roxlo, y la monografía de tipo pedagógico, valiosa pero limitada (Real de Azúa, 1964).

Emir Rodríguez Monegal -quien, al igual que Real de Azúa, no puede señalarse como complaciente- afirma que Zum Felde fue "el único crítico responsable que produjo la generación de 1917, el único que asumió la reseña periódica de libros nacionales con la conciencia de los riesgos que implica y la responsabilidad social que arrastra”. Acallado por la acusación 
de plagio, "con sus ribetes de pequeño escándalo publerino", significó la "supresión de una actividad crítica exigente y comprometida consigo misma". Se abrió así un paréntesis de "ausencia total de una crítica literaria responsable y orientadora”, panorama que solamente se transformó con la apertura de Marcha en 1939 (Rodríguez Monegal, 1966: 51-52).

Coincidente con el ideario trazado en su ensayo de 1917, en la década de los veinte fue en Uruguay el teórico que alentaba, en todas las expresiones artísticas, creaciones que afirmaran "esencias nacionales", aunque se preocupara también de los valores estéticos y de la articulación entre innovación y tradición, como mostró en la revista La pluma. También de esta década son sus libros Proceso histórico del Uruguay (1919), ${ }^{8}$ Crítica de la Literatura Uruguaya (1921), donde reunió parte de sus artículos de El Ideal, y Estética del 900 (1929). En el primero, el autor estudia la construcción de Uruguay y su evolución utilizando conceptos sociológicos y tomando en consideración factores del territorio, composición étnica, economía y cultura. Estética del 900 reúne un ciclo de conferencias dictadas en la Facultad de Humanidades de la Universidad de La Plata, en septiembre de 1927, destinadas a examinar las corrientes estéticas posteriores a la Primera Guerra Mundial; esas intervenciones estaban orientadas a dar respuesta a la cuestión de la perspectiva americana en relación a las mudanzas contemporáneas de los movimientos artísticos, y en un sentido más general a las innovaciones culturales que se estaban desplegando en Occidente. De esta manera Zum Felde va orientando sus elaboraciones al enriquecimiento de las posiciones esquemáticamente trazadas en El Huanakauri.

Terminado de manera abrupta el ciclo periodístico de los años veinte por un extraño supuesto plagio incurrido en una situación confusa- viaja en 1931 a Europa, después de haber publicado una de sus obras capitales: Proceso intelectual del Uruguay y crítica de su literatura (1930). En esa obra, el autor ordena y valoriza la producción intelectual uruguaya, desde el lejano pasado colonial. Tal como el mismo Zum Felde ha expresado, en su Proceso ha encarado el fenómeno intelectual desde las perspectivas de la sociología, la psicología y la estética. A Proceso... le siguieron otros dos libros que redondearon la temática tratada allí: Índice de la poesía uruguaya contemporánea (1935) y La literatura del Uruguay (1939).

\footnotetext{
8 Reimpreso en varias oportunidades; algunas tesis de este libro se habían anticipado en El Uruguay en el concepto sociológico, de 1911.
} 
Luego publicó El ocaso de la democracia. Apuntes de una nueva filosofía política (1939), donde revisó la situación política mundial, y El problema de la cultura americana (1943), que nos ocupará aquí, donde planteará con mayor rigor y madurez las tesis de El Huanakauri. La obra de crítica e historia literaria se cerró con la publicación en México de Índice crítico de la literatura hispano-americana, el primer volumen dedicado a Los ensayistas (1954), y el segundo a La narrativa (1959). Finalmente, convertido al catolicismo, publica dos nuevos libros: Cristo y nosotros (1959) y Diálogos Cristo-Marx (1971).

\section{INTERROGACIÓN Y CRÍTICA EN EL PROBLEMA DE LA CULTURA AMERICANA}

De la rápida revisión que hemos efectuado del itinerario de las ideas y de la obra de Zum Felde podemos proponer que su libro El problema de la cultura americana representa una trabajada síntesis, producto de un largo proceso de elaboración cuyo punto inicial se encuentra en El Huanakau$r i$. El trabajo de indagación en torno a la entidad americana en que se empeñó el pensador uruguayo a partir de la segunda mitad de la década de 1910 culminó transcurrido más de un cuarto de siglo con los ensayos publicados en El problema... en 1943. Se nutrió de una línea de crítica radical al racionalismo positivista alimentado básicamente por la influencia de Nietzsche y, más difusamente, por el esteticismo modernista y sus fuentes, direccionado todo a la consecución de una reflexión de búsqueda ontológica en torno a los fundamentos de la entidad de la construcción cultural americana dentro de un horizonte historicista.

Bien señala Arturo Ardao algunas tendencias de transformación en la filosofía tal como se operaron en Uruguay a partir de la década de 1920, intensificándose en la de los años treinta, bajo el influjo de lo que él señala como "la filosofía contemporánea, dominada por la reflexión sobre el hombre y la cultura", y en la que ocupa un lugar importante Alberto Zum Felde. Primero, y con gran perspicacia respecto a la ambigüedad de las relaciones entre modernismo y positivismo, Ardao puntualiza que es reconocible un distanciamiento del "espíritu naturalista que inspiraba todavía, en el fondo, a Rodó y Vaz Ferreyra”. Seguidamente reconoce la enorme influencia ejercida por José Ortega y Gasset, especialmente entre los años 1930 y 1936, como vehículo de recepción de la filosofía alemana a través de sus conferencias en Argentina, la Revista de Occidente y las publica- 
ciones de su editorial: es el momento "en que se define la nueva situación filosófica, que -para Ardao- habría de consolidarse en los años posteriores, principalmente a lo largo de la década del cuarenta, lejos ya de la transicional etapa orteguiana". Hablamos, en lo fundamental, de Husserl, Hartmann, Scheler, Heidegger (Ardao, 1956: 175-176). Vemos, entonces, el entorno de Zum Felde, pero también su posición de adelantado de este proceso de renovación filosófica que él vinculará a un objeto específico, la cultura americana como fundamento de entidad, y que Ardao caracteriza claramente en un campo de más vasto alcance:

[...] la cultura, concebida como el mundo que el quehacer espiritual del hombre yuxtapone al mundo de la naturaleza. Sea que se inquiera sobre la cultura en sí misma; o sobre objetos que pertenecen a su ámbito; o sobre objetos que le sirven de fundamento, como los valores; o sobre el sujeto que la realiza, o sea el hombre, en su existencia y en su historia; o sobre una determinada cultura histórica, se trata de un tipo de pensamiento directamente condicionado por las nuevas circunstancias universales de la filosofía, en la línea de especulación culturalista tomada en su más alta significación (Ardao, 1956: 177).

Resulta sustantiva la recuperación de la contribución de Zum Felde, realizada por el filósofo y crítico oriental en un momento crucial de constitución del moderno pensamiento latinoamericano. Con la suma de la contribución del autor uruguayo podemos revelar una nueva vertiente de la edificación de la problemática y los elementos conceptuales del latinoamericanismo en el periodo posterior a la Segunda Guerra Mundial, otorgándole -de ser cierto lo que postulamos en este trabajo- una genealogía más compleja que la sola reelaboración de la discusión acerca del "ser" mexicano -instituida en buena medida por Samuel Ramos y continuada por Paz- articulada con el horizonte filosófico del circunstancialismo historicista de Ortega y Gasset. A su vez, hay que considerar que el horizonte de historicidad proporcionado a partir de Meditaciones del Quijote fue, a su vez, renovado intensamente por José Gaos, en particular con su traducción de El ser y el tiempo de Heidegger publicada en 1951, y por el vigor hermenéutico provisto por la traducción de la obra de Dilthey a partir de 1944, realizada también en México por Eugenio Ímaz.

Tomar en consideración la vía abierta por Zum Felde en la coyuntura intelectual de América Latina de mediados de los años cuarenta no sólo complejiza las fuentes del pensamiento de Leopoldo Zea sino que abre 
interesantes perspectivas que deberán profundizarse respecto del diálogo no siempre evidente ni explícito establecido entre el filósofo mexicano y las elaboraciones contemporáneas del sur del Continente. La historia intelectual, tan en boga en la actualidad, tiene abierto un campo extenso y de suma productividad en el esclarecimiento de las redes y contactos intelectuales, no siempre amistosos o comprensivos por lo demás, que establecieron -desde la década de 1940, y en forma más intensa en la inmediata posguerra- el nuevo campo de los estudios acerca de América Latina en sus múltiples variables y territorios de interés y que hasta ahora no se han estudiado en sus diversas manifestaciones concretas y numerosas interconexiones.

El problema ontológico de la entidad americana. El libro de Zum Felde comienza con una tesis fundamental, que es el núcleo de su sentido y que marca todo su desarrollo posterior:

El problema de nuestra cultura [...] de la cultura de esta América Latina, y más precisamente aún, de la cultura de los latino-americanos, es, en esencia, el problema de nuestra propia entidad (Zum Felde, 1943: 9).

La formulación se redondea pocas líneas más adelante:

Este planteamiento del problema, lo desplaza y eleva del terreno simplemente objetivo en que hasta ahora estuvo situado, para categorizarlo como un imperativo ontológico, identificándolo con el problema de la entidad del hombre americano en sí mismo; y este principio de definición del ente americano -realización histórica de un ente humano abstracto, en las condiciones de lugar y de tiempo que su destino le ha asignado- es un postulado de la conciencia -inmanente y trascendente a la vez-, que supera todo mero pragmatismo nacionalista (Zum Felde, 1943: 10).

Vemos presente el historicismo, manifestado aquí en forma palmaria como circunstancialismo orteguiano, superando reciamente la tentación de la superficial abstracción universalista que Zum Felde desacreditará a lo largo de su obra como mera coartada de los académicos desentendidos del drama americano, actuando como agentes del colonialismo cultural. Existe en la argumentación del pensador uruguayo un imperativo ético subyacente en tanto se plantea el abordaje de la cuestión de la entidad americana como necesidad vital, aunque este tema no está desarrollado y muy pocas veces, inclusive, alcanza el nivel textual explícito. El impulso ético del latinoamericanismo -elemento central de su conformación como ideología, de fuerte impacto en la cultura política de la región luego de la 
Segunda Guerra Mundial y exacerbado después de la revolución cubana-, fortalecido posteriormente a través de la recepción del existencialismo francés con las repercusiones difusas pero eficaces del "compromiso" sartreano, será un elemento insustituible en tanto agrega un elemento de gran vigor y originalidad respecto de otro tipo de estudios cuyo objeto es América Latina pero sus alcances son simplemente académicos.

En El problema... el hombre americano presente en la coyuntura histórica signada por la crisis de la cultura occidental y por la inautenticidad de su cultura que le impide asumir una entidad propia, sufre vitalmente el drama ontológico "como realidad [actual] patética del ser" (Zum Felde, 1943:11). Este drama representa la realidad total de la existencia históricamente determinada, sin ninguna posibilidad -como dijimos- de evasión en términos de una coartada universalista. Esta pregunta por la entidad constituye en términos históricos una situación inédita, no experimentada por ningún otro pueblo anteriormente, es un problema exclusivamente sudamericano,

[...] ya que los pueblos de Europa -nuestros mayores-, poseen una personalidad históricamente definida, una idiosincrasia tradicional; y sus individuos, cultos o incultos, participan de esa idiosincrasia, encarnan esa personalidad de modo consustancial, que radica en la subconciencia (Zum Felde, 1943:16-17). ${ }^{9}$

El coloniaje intelectual. Zum Felde diagnostica la situación americana como de "coloniaje intelectual" y, en consecuencia, "cultural" (Zum Felde, 1943: 28, 31). "La americanidad que hay en el hombre de América -americanidad de hecho- no ha alcanzado todavía conciencia de sí misma como para poder definirse intelectualmente", una situación cuasi virginal que hace de América "un continente sin descubrir", sin camino trazado para el explorador ni moradas de abrigo al viajero, una situación de intemperie en la que "hay que abrirse por sí mismo los caminos, orientándose en medio de lo confuso y de lo indefinido". Escenario caracterizado por la falta de autenticidad de la cultura, que sólo se constituye sobre un "acopio de materiales librescos y es un eco del pensamiento de ultramar". Sus intelectuales son instrumento del coloniaje cultural, elementales repetidores

9 Zum Felde utiliza principalmente el concepto "americano", pero en ocasiones se refiere a lo "sud-americano", sin que la distinción obedezca a alguna intencionalidad conceptual fuerte; la utilización del segundo término mencionado responde, más bien, a un énfasis de concreción cuando lo solicita la argumentación. 
de conceptos importados sin ninguna capacidad crítica, que enjuician el hecho americano con criterios o prejuicios europeos, "una intelectualidad común [que] se vanagloria ingenuamente de su saber libresco y se decora con el lujo rastacuero de las citas" (Zum Felde, 1943: 30).

La tarea se impone, aunque no sea fácil de realizar:

Desprenderse de la letra de los textos, emanciparse de las fórmulas de la sociología y de la retórica, libertarse de toda teorética universitaria, afrontar nuestra propia realidad con un sentido lúcido, directo, desnudo, tal es la empresa difícil y necesaria que toda conciencia debe cumplir en sí misma, y previamente, para empezar a estar en condiciones de americanidad intelectual (Zum Felde, 1943: 31).

Asume como propia la historia de Occidente, sobre ella se traza la genealogía americana, utilizando así un concepto nietzscheano de enorme sentido heurístico y gran valor metodológico, ya que sitúa la reflexión propia en un lugar activo, constituyente protagónico de su pasado y no receptor pasivo de una historia irreductiblemente impuesta por herencia, resultado del peso del desarrollo evolutivo, tal como la pensaba el historicismo positivizado de finales del siglo xix. La historicidad de Occidente se asume voluntariamente como propia, -resultado de una operación racional sobre el transcurrir histórico de la modernidad en la que se inserta América-, pero sólo como fundamento del devenir, que es americano; América como fuente proyectual autónoma de su futuro, en el corazón de una nueva matriz construida sobre la base de un radical giro en la posición de pensamiento y elocución.

Heraldo de tiempos nuevos, el filósofo montevideano asegura, retomando la imagen de la mirada que desde Esteban Echeverría subyuga a los pensadores de la identidad americana: "Tenemos que mirar con ojos americanos a Europa -y no a América con ojos europeos- y valorizar su historia en función de nuestro porvenir. Ésta es la etapa de nuestra conciencia y de nuestra entidad que ahora comienza" (Zum Felde, 1943: 32). Acepta la universalidad de lo humano

[...] pero el hombre americano ha de encarar esa universalidad de su historia, en el tiempo y en el espacio, con el criterio y la medida de su propio devenir histórico. América es, para nosotros, el mirador de nuestra perspectiva, el meridiano de nuestras valoraciones, el centro de convergencia de todos los caminos de la historia (Zum Felde, 1943: 32). 
Frente a ciertos desvaríos actuales de un autoproclamado progresismo en cuanto a la autoctonía exclusivista de una mirada americana, desligada completamente de Occidente y, es más, antioccidental en virtud de la auto-postulada legitimidad de una supuesta entidad originaria de algunas etnias - un reclamo de pureza étnica de equívocas raíces racistas y de una asombrosa y prejuiciada ignorancia de la dialéctica histórica de las culturas-, podemos subrayar la complejidad y alcances de un pensamiento como el del autor de El Huanakauri. Él habilita la posibilidad de fundar una entidad americana con personalidad propia sin negar el concierto del desarrollo histórico mundial, y alerta respecto a la construcción de su propia historicidad en tanto genealogía y en tanto devenir futuro, integrando los componentes diversos resultado del proceso histórico.

Crítica punzante del ambiente intelectual del coloniaje. Zum Felde se manifiesta contra el "andamiaje de tópicos", la "abigarrada glosa de sus lecturas y un tejido habilidoso de citas", "lamentables casos de indigencia del criterio propio", contra el bizantinismo intelectual libresco que presenta la realidad cultural americana (Zum Felde, 1943: 28-29).

El mundo valorable acaba -visto desde Europa-, antes de llegar a este trópico nuestro, aturdido de loros. Cierto que hemos tenido, y seguimos teniendo, demasiados loros sabios por estos trópicos -y sub-trópicos- del continente; y que su parlería retórica y mulata, ahoga las pocas voces altas que dignifican nuestra literatura. ¡He aquí -Zum Felde levanta la voz- una de las grandes tareas que es preciso emprender, entre las primeras, si queremos llegar a ser algo serio en el mundo: la matanza de multitud de loros literarios, cuya parlería apesta nuestros ambientes en promiscuidades negativas! Cuando hayamos conseguido despejar el clima intelectual de esa calamitosa fauna, tal vez se pueda ver mejor, desde lejos, los verdaderos valores aislados que poseemos (Zum Felde, 1943: 35-36).

Como bien afirmó Arturo Ardao, nuestro autor "ha sido severísimo" con "la cultura académica, tal como suele presentarse en nuestros países, ingenuamente libresca y europeizante" (Ardao, 1956: 179). Quizás desde la invectiva de Zum Felde podríamos pensar el estilo de Zea, su renuencia a las citas de sus fuentes, su afirmación perentoria de una certeza subjetiva intensamente reiterada, una renovación que pienso rehuía deliberadamente complacencias y guiños, sutilezas y amaneramientos estilísticos en pro de una rotundidad de razonamiento. Zea desdeña barroquismos, trabaja con una prosa que a veces se torna seca y leñosa, pero que se erige precisamente como contracara del parloteo intrascendente y cortesano de 
esa forma peculiar a la que dirige Zum Felde su sarcasmo. Forma de la crítica, asumida desde la elección estilística.

Lo que llamamos "cultura" -nos dice-, suena a hueco todavía en esta América, precisamente porque es sólo una retórica de la cultura, dentro de la cual no hay más que mera letra, sin que la vivifique el espíritu de una entidad. En vez de auténticas estructuras, con cimientos en la realidad histórica, no hay, en nuestros países, sino el papel pintado de unas bambalinas, entre los cuales, la minoría ilustrada representa la comedia de la cultura. Os alejáis un poco de los centros didácticos, y ya estáis en plena barbarie vernácula; más aún: os alejáis del núcleo europeizado a los arrabales medrosos, y ya os encontráis en otro mundo: en el mundo de la realidad nebulosa de este continente, donde cada ciudad es el bazar de la industria extranjera (Zum Felde, 1943: 37).

Formas parasitarias de la cultura. Nuestra cultura latinoamericana es una de esas formas. Hemos vivido y seguimos viviendo todavía, absolutamente a expensas de la producción europea [...] Dependimos y dependemos enteramente de la fenomenalidad de su vida cultural; su actualidad es nuestra actualidad; sus escuelas, sus estilos, sus modas, son las nuestras; no tenemos otras, no tenemos nada propio, ni para nosotros, ni para ellos; no aportamos nada; no producimos, consumimos; no existimos aún en el proceso de la cultura universal (1943: 37-38).

Este diagnóstico fue compartido ampliamente por algunos de los pensadores más inquietos de este momento intelectual de búsqueda renovadora -Mallea, por ejemplo, y muchos otros integrantes del grupo de la revista Sur; H. A. Murena algo más tarde- y de diversas formas penetró en estratos muy profundos de la realidad cultural de América Latina en la época, siendo muy intenso el impacto en los análisis de la realidad y la prospectiva política, en particular a partir de la década de los treinta, aunque pueden reconocerse autores y tendencias anteriores a esa fecha y a esa evidente crisis. En Uruguay resulta interesante un derivado un tanto posterior de estas posiciones, presente en la obra de Roberto Fabregat Cúneo, quien encuentra en el “amorfismo cultural del continente" el fundamento del "drama sudamericano". ${ }^{10}$ Alguna resonancia orteguiana (de la segunda visita a Argentina), muy visible, está también presente en estas apreciaciones.

10 El libro de Roberto Fabregat Cúneo es Caracteres sudamericanos, de 1950, cf. Ardao, 1956: 177-178. Un trabajo de referencia para esta significativa tendencia intelectual, circunscripto a Argentina pero con posibles extensiones a América Latina es Kozel, 2008. 
Diagnóstico "del problema de nuestra cultura": la inautenticidad. Prosigue Zum Felde en un diagnóstico "del problema de nuestra cultura": el adjetivo es desolado (1943: 28).

Pero la cultura de tipo parasitario no es una cultura del espíritu y de la vida, sino de la forma y de la letra; cultura superficial y postiza, falsa cultura; porque el espíritu es original o no existe; no puede vivir sino de su propia raíz ontológica y no puede manifestarse sino como entidad categorial. La cultura del espíritu es una realidad intrínseca del ser cuya condición vital es la soberanía. No hay que dejarse engañar con esa apariencia que consiste en la extensión de escuelas, universidades, academias, certámenes; porque todo eso es sólo andamiaje formalista y queda sólo en formalismo y apariencia si carece de sustantividad propia que le dé un contenido vivencial y un valor auténtico. La cultura, en la mayor parte de esta América, existe en estado de falsificación; es cultura de apariencia y no de realidades, de parecer y no de ser, puesto que no tiene arraigo en la propia entidad y vive del préstamo y de la glosa. Es comedia de la cultura y no verdad viviente esta que aquí tenemos, pues toda ella está en los ritos, en las palabras, en la exterioridad, no en la conciencia. El hombre culto latino-americano, vive engañado y engañándose, creyendo que sus figurines de ultramar son él mismo. Helo aquí al tanto de la última palabra que, en materia de estética o de sociología, le traen las publicaciones extranjeras, y creyendo, a menudo ingenuamente, que por ese mero hecho de información y copia él es ya un hecho de cultura (Zum Felde, 1943: 38).

El trasfondo nietzscheano de sus formulaciones es revelador de la impronta más decisiva de la conformación de su pensamiento. Pero una resonancia más inmediata, que de seguro refuerza aquellas connotaciones, es la de Ezequiel Martínez Estrada, también apasionado lector de Nietzsche. El problema de la apariencia, de la falsedad e inautenticidad de la cultura tal como lo argumenta Zum Felde presenta fuertes semejanzas con contenidos provenientes del análisis de la cultura argentina efectuados una década antes en Radiografía de la pampa, publicada en 1933, y proseguido con ahínco en las tres décadas siguientes, particularmente en La cabeza de Goliat (1940) anterior también al referido libro de Zum Felde-, Sarmiento (1946) y Muerte y transfiguración de Martín Fierro (1948). El tono sarcástico y admonitorio del ensayista argentino se desliza conscientemente, aunque un tanto contenido, en la prosa del uruguayo, como elemento estilístico decisivo para la ruptura de la molicie bizantina y para la configuración de un espacio ético-crítico, más acentuado en su primera dimensión en el ensayista de Radiografía, pero atemperadamente presente también en Zum Felde. 
La conclusión tremendamente pesimista, de cuño alberdiano, de $R a$ diografía de la pampa, en la que la barbarie nuevamente asoma entre los pliegues de la civilización postizamente adquirida -el chiripá mañosamente reaparecido y entrevisto detrás del chaleco de punto, la galera y el frac- (Crespo, 1994), se diluye en Zum Felde básicamente porque su análisis no se instala en la dicotomía sarmientina de civilización y barbarie, sino que se ha conscientemente deslizado al eje de la autenticidad ontológica enfrentada a la superficialidad imitativa y carente de vitalidad; tránsito en verdad decisivo para el entero replanteamiento de la cuestión de la cultura americana, es cierto que insinuado anteriormente por valiosos ensayistas entre los que se encuentra, en clave irónica, el joven y criollista Jorge Luis Borges y, fundamentalmente, las desopilantes, desmesuradas e incisivas propuestas de los hermanos Andrade; más tarde reaparecerá en la novela de Leopoldo Marechal Adán Buenosayres. La frecuentación de la vanguardia en los años veinte, diría más, el exhaustivo conocimiento de ella por parte del ensayista uruguayo a partir de su práctica de creación y el constante ejercicio periodístico de la crítica literaria, construye este nexo complejo entre la poética y la reflexión vanguardista con el filosofar latinoamericanista posterior en dos décadas.

La búsqueda de lo "propio americano". Es por ello, por esa acuciante necesidad de autenticidad, que la tarea que se impone como imperativo para Zum Felde es precisamente la búsqueda de lo propio americano como fundamento de autenticidad en la interacción universalista

Elaborar una cultura espiritualmente valiosa -valiosa como finalidad humana-, es buscar, fundamentalmente, la expresión formal viviente de una categoría del ser americano (Zum Felde, 1943: 25).

La empresa que tenemos por delante, los latino-americanos de esta generación -y de las que vendrán- es la de construir nuestro propio órgano de cultura, empresa hacia adentro, esfuerzo introspectivo, definición de auto-conciencia: la más difícil de las emancipaciones. La libertad espiritual como toda libertad, y aún en mayor grado que cualquier libertad material, es un bien que debe ser conquistado por el propio ser (Zum Felde, 1943: 55).

Podríamos,

[...] seguir viviendo así, como hasta hoy, bajo esta fácil tutela, sin plantearnos cuestiones de fondo, sin angustiarnos en nuestra propia inquisición, sin esforzarnos en definir nuestra identidad. Y sin vivir nuestro drama; volviéndole la espalda, despreocupadamente, a nuestra realidad; aceptando, cínicamente, nuestra posición [...] (Zum Felde, 1943: 87). 
Pero no, debe adoptarse la agonía, la lucha,

[...] sentir el drama es sentir el dolor del órgano enfermo; que nos duela, eso es lo primeramente necesario para que nos pongamos en actitud. Una conciencia dramática del problema es el principio de la entidad; lo que duele es la sensibilidad de la raíz, que empieza a manifestarse (Zum Felde, 1943: 87).

Es dolor unamuniano el del despertar de la conciencia americana. Una voluntad de ser como principio de desarrollo de la identidad ontológica, como disparador dramático de la conciencia americana, conciencia angustiosa del "estado de no ser",

[...] angustia activa -alecciona- la que se tiende apasionadamente hacia su fin. Pues, si aún no somos, si lo que hemos de ser pertenece al futuro, ¿qué sentido tiene todo lo que hacemos, sino tiende dramáticamente hacia la entidad? [...] Sólo aquello que sea, en alguna forma, expresión de esa conciencia del drama ontológico de la americanidad, sólo aquello que tienda, de algún modo, a la realización de nuestra voluntad de ser, tiene un valor y un sentido, frente al mundo y frente a nosotros mismos: el valor de su autenticidad, el sentido de su presencia (Zum Felde, 1943: 97).

Las tareas del tiempo presente. Un punto esencial de la reflexión de Zum Felde se despliega en relación al tiempo presente, en cuanto supone un momento de disponibilidad que, visto retrospectivamente, induce a pensar en la gran oportunidad que se abría al pensamiento latinoamericano en esa búsqueda de identidad ontológica desplegada a la contemporaneidad. Oportunidad que, a todas luces, aprovechó luego Leopoldo Zea para trazar una trayectoria fundamental anclada precisamente en la percepción ajustadísima del momento que se vivía. Uno podría preguntarse, y conjeturar ahora, en cuánto del trazado del proyecto zeísta tuvo que ver esa adecuada descripción de la coyuntura propuesta por Zum Felde en el umbral de apertura de la carrera intelectual de Zea -y alguna certidumbre nos da la reseña que comentamos más abajo-, que sin duda el filósofo mexicano hizo suya en el trazado tanto de la estrategia de participación como en el diseño de en su propia agenda de intervención.

Un primer acicate, que por otra parte cuestiona duramente algunas de las propuestas nodales del arielismo, es la comparación con Estados Unidos, que Zum Felde reconoce como el hogar de Edgard Allan Poe, de Emerson, de Walt Whitman, de William James entre otras figuras de amplio reconocimiento, de "eminencia mundial", mientras que América Latina hasta el momento no dispone de ninguna. Esto dibuja una paradoja 
respecto a las postulaciones del Ariel: ¿cómo los utilitarios y prácticos estadounidenses han logrado figuras de mayor talla y trascendencia en los reinos de la especulación filosófica y la creación literaria que los cultores de lo intelectual y de lo estético? ¿Cómo los “arielistas”, se pregunta Zum Felde, no sólo se ven superados en vías férreas, aeropuertos, edificios, estadios, colegios y bancos, sino también en el pensamiento y en la poesía? Dice entonces:

De tan desconcertante comprobación, ¿debemos inducir conclusiones pesimistas? ¿probaría, este hecho paradojal, que, en efecto, -y a pesar de nuestra vocación humanística- nos han sido negados, a los de esta América Latina, la originalidad y el genio creador...? Lo ocurrido hasta hoy, ¿autoriza a sentar una tesis negativa tan terminante y desalentadora? (Zum Felde, 1943: 40).

La respuesta es clara, se trata de un fenómeno de inhibición espiritual determinado por peculiares condiciones del desarrollo histórico.

Pero la etapa de nuestro neocolonialismo cultural ha de ser también traspuesta y superada, aunque el proceso sea más lento y difícil. Grandes síntomas lo evidencian, desde ya. Los tiempos de la nueva etapa están teniendo comienzo (Zum Felde, 1943: 41).

La reflexión sobre el momento del presente tiene varias aristas de sumo interés en la argumentación de Zum Felde. Fue la coyuntura de gran complejidad de la Segunda Guerra Mundial la que hizo evidente la "crisis histórica de la cultura occidental, a cuyo trance de descomposición asistimos", creando una ventana de oportunidad para marcar la hora del levantamiento espiritual de América Latina, tal como la crisis de la monarquía española en 1808 significó el toque de campana para la "emancipación del coloniaje político". Para nuestro autor se abre una época acaso heroica, de "desconcierto de nublado signo", de intemperie por la plena quiebra de valores europeos, en la que "hallaremos nuestro propio camino y de la cual saldremos en posesión de nuestra mayoría de edad".

El eclipse de Francia nos ha dejado entregados a nosotros mismos; es, quizás, el momento de intentar andar por nuestra cuenta [...] ensayar nuestro propio camino (Zum Felde, 1943: 52).

Acaso necesitamos quedarnos solos para poner en ejercicio nuestras energías latentes y obligar nuestra capacidad de autonomía. El autor de este ensayo acerca de nuestra angustia, siente como presagio promisor que él aparezca en la hora incierta de esta crisis (Zum Felde, 1943: 42). 
Este tipo de reflexión nos recuerda el momento en que los jóvenes impulsores de la Reforma Universitaria de Córdoba de 1918, enfrentados a la crisis civilizatoria que supuso la Primera Guerra Mundial planteaban en el célebre Manifiesto Liminar de Córdoba la presencia de una "hora americana" de regeneración de valores y de creatividad de la cultura.

Toda entidad americana debe ser anfictiónica. Es en la amplia anfictionía latino-americana, y no en el localismo nacionalista, donde radica la virtud más alta de nuestra personalidad y la potencialidad histórica de nuestro devenir (Zum Felde, 1943: 47).

Podemos señalar aquí una fuente importante de Zum Felde -y, si la propuesta de este trabajo es acertada también indirectamente de Zea- respecto a las posibilidades que abría la coyuntura presente para la autonomía y la proyección cultural americana. Zum Felde expresa adhesión franca, admiración incluida, por Waldo Frank, destacado novelista y ensayista estadounidense, miembro del grupo de la revista Sur de Victoria Ocampo, en Buenos Aires. Esto no sólo indica una filia intelectual de interés, sino que remite a una acción concreta en el contexto político específico de la Segunda Guerra Mundial en el que se escribió El problema de la cultura americana. El Departamento de Estado había solicitado a Frank en abril de 1941 que realizase una gira de conferencias contra el fascismo en Sudamérica, pero el escritor rechazó la invitación. Cartas de sus amigos de la región y el ataque japonés a Pearl Harbor hicieron que reviera su posición y entre abril y octubre de 1942 dictó una serie de conferencias, repetidas en Argentina, Brasil, Chile, Uruguay, Perú y Colombia, como un esfuerzo para contrarrestar la propaganda nazi en esos países. Exitosa y controvertida, un momento culminante de esta gira fue la declaración de Frank como persona non grata por el gobierno argentino del presidente Castillo, y el ataque que sufriera un día después en su alojamiento en Buenos Aires, con heridas que motivaron su hospitalización, lo que le dio una gran notoriedad rubricada por una nota de tapa en el New York Times.

El planteamiento inicial de Frank en su primera charla, "La Guerra que está debajo de la guerra”, urgía a los latinoamericanos a luchar por sí mismos y por sus propias razones contra el fascismo. En la segunda exposición, "Ustedes y nosotros" Frank predecía que si lograban esto un nuevo mundo cultural y artísticamente superior podría emerger, un mundo que realizaría el destino de las Américas. Las dos siguientes conferencias tenían un título común: "Los dos caminos". En su primera sección, 
"Hacia la derrota del hombre", se dirigía a la juventud latinoamericana para prevenirla de unirse a las bandas fascistas que representaban el anti-humanismo, argumentaba no definirse por la izquierda o la derecha, sino por la Humanidad, llamándola a construir la Ciudad del Hombre. En la segunda sección, "Hacia el destino humano", en un mensaje atravesado de espiritualismo, Frank aseguraba que luchar y derrotar al fascismo aseguraba la realización plenamente humanística de la sociedad, y ese era el núcleo de su argumentación política y social. El silencio podría ser de muerte o de renacimiento. En la quinta conferencia "Los elementos del nuevo mundo en los Estados Unidos", Frank ponía a discusión los objetivos gubernamentales estadounidenses respecto de América Latina, con una renovada mirada rooseveltiana de la "buena vecindad". ${ }^{11}$ Las conferencias fueron publicadas el mismo año 1942 en Buenos Aires por una importante editorial de republicanos españoles (Frank, 1942). Es seguro que Zum Felde escuchó a Frank en su visita a Montevideo -era en ese momento director de la Biblioteca Nacional de Uruguay-, y su libro trasunta la recepción entusiasta del mensaje del estadounidense, en particular el destino de una cultura americana superior planteada en la segunda conferencia, $y$ el horizonte humanista y espiritualista trascendente como fundamento axiológico de superación y organización de la cultura.

Universalismo / Occidentalismo / Americanismo. La cuestión crucial de la pertenencia o no de América a Occidente, y en caso afirmativo de las modalidades y formas de esta pertenencia, presenta trazos potentes en Zum Felde, dentro de una orgánica concepción historicista del desarrollo cultural universal, una dialéctica de culturas en interacción y en transformación, a la que no debe ni podría sustraerse la cultura americana auténtica, históricamente viva y por ende real.

Para nosotros, los latino-americanos, la condición de occidentalidad es tan irrenunciable como la condición de americanidad [...] Pero, somos occidentales de América, no de Europa. Ocupamos una posición histórica especial; tenemos nuestras determinantes propias, dentro del vasto sistema universal del occidente [...] la cultura occidental, universal, para ser hecho viviente y función del hombre real, aquí en América, tiene que americanizarse, asumir modalidades conforme a nuestras determinantes.

11 La referencia documental de la gira de Frank en University of Delaware, Library, Special Collections Department, Waldo Frank Papers 1922-1965, Serie II, Writings by Waldo Frank, folders 20-23. http://www.lib.udel.edu/ud/spec/ findaids/frank.htm. Consulta: Abril de 2015. 
De lo contrario, nuestra posición es falsa; y la cultura misma, más aparente que real [...] Americanidad y universalidad no son términos opuestos sino complementarios, integrativos. La universalidad se define concretamente en la americanidad. Esto constituye la entidad histórica viviente de un orden de cultura (Zum Felde, 1943: 78-79).

El plano del arielismo ha de ser superado, ahora, por un sentido de la personalidad $-y$ de la americanidad- más profundo, más ontológico. [...] Se trata de superar la condición de colonialismo cultural en que hasta hoy permanecimos, para afrontar la autonomía y la responsabilidad de la elaboración propia; se trata de salir de la etapa de supeditación del aprendizaje liceal, en que nuestra intelectualidad ha vivido hasta el presente, para firmar el imperativo de la propia entidad (Zum Felde, 1943: 109-110).

Zum Felde acepta la influencia del misticismo individualista de Unamuno y del relativismo crítico de Ortega, tendiente a contrarrestar la presencia francesa, "ambos influjos sólo se han ejercidos sobre un sector muy minoritario de la intelectualidad latinoamericana, quizás el más selecto -agrega muy sutilmente-, pero no el predominante" (Zum Felde, 1943: 127-128). Un claro deslinde con La raza cósmica de Vasconcelos, utópica, "acaso meramente literaria", con el cual, entre otros, mantiene una marcada polémica sin mencionarlo: la de oponerse tenazmente al hispanismo como tendencia cultural del franquismo, como resabio imperial al que hay que rechazar (Zum Felde, 1943: 132-133). En 1943 esto significaba una abierta toma de posición, no sólo referido a España y al conflicto mundial, sino al alineamiento de fuerzas intelectuales y políticas en el interior de los países del Plata: en Buenos Aires y en Montevideo el franquismo constituía una fácil amarra del reaccionarismo católico, poco afín con el fascismo italiano y mucho menos con el nazismo alemán.

$\mathrm{Su}$ afirmación definitiva en torno a la dinámica cultural en relación a los otros grandes espacios de civilización no deja lugar a ambigüedad alguna, y es llamativa la coincidencia que expresará posteriormente Zea en este tema central:

Seremos americanos en la medida en que seamos universales; y universales en la medida que seamos americanos. Pero universales por integración y síntesis; y americanos en virtud de nuestra posición histórica. La universalidad es nuestra categoría propia de cultura y la americanidad el signo de nuestro destino en la historia (Zum Felde, 1943: 147). 


\section{EL COMENTARIO DE LEOPOLDO ZEA}

Unos meses después de la aparición de El problema de la cultura americana -cuyo colofón señala que se terminó de imprimir en Buenos Aires el 24 de diciembre de 1943-, en el último número de 1944 de Cuadernos Americanos, quizás ya el principal vehículo de contacto entre los intelectuales del continente junto con Repertorio Americano de Joaquín García Monge, Leopoldo Zea publicó su reseña del libro de Zum Felde (Zea, 1944: 126-130). A semejanza del texto comentado, el joven ensayista mexicano, que comenzaba recién su carrera intelectual, también abre su escrito con un señalamiento nada trivial: subrayaba la situación de "crisis actual de la Cultura Occidental" -en tácita alusión a la Segunda Guerra Mundial todavía en curso y a los efectos devastadores por ella producidos- que planteaba un escenario inédito, impensado hasta esas circunstancias: la cuestión de la continuidad de esa cultura. La crisis de la cultura europea alcanza también, con inusual fuerza, a una forma de vida cultural que se ha derivado de ella, la americana, y en particular la de los pueblos iberoamericanos. Deben también anotarse, en este presente perturbado, las graves consecuencias humanas, políticas y culturales aparejadas por el desenlace de la Guerra Civil española, que Zea obviamente también tenía presente en forma inmediata, básicamente por su relación con Gaos y la presencia de los exiliados españoles en México. Pero, a la vez, la crisis abría un hasta hacía poco impensado horizonte de oportunidades.

Zea diseña un dilema que desafía a los intelectuales de América: dejarse llevar por el caos en espera del recurso desde fuera que lo resuelva, o enfrentarse a éste "buscando en sus propias entrañas una solución que lo anule" (Zea, 1944: 126). Este camino, de adoptarse, significaría asumir "la mayoría de edad" intelectual, en el decir de Alfonso Reyes, y en este caso América podría estar llamada a ofrecer al mundo "una nueva síntesis cultural", "una nueva y grande síntesis de la cultura y de la historia”, citando a Zum Felde (Zea, 1944: 129). Esta perspectiva optimista, en tanto América sería el nuevo núcleo del desarrollo cultural como heredera y prolongación de Occidente, presenta una continuidad evidente con la posición de los jóvenes de la generación de la Reforma Universitaria iniciada en 1918, inmediatamente de la tragedia de la Primera Guerra Mundial, para los que América constituía la reserva humana y cultural sobre la que podría rehacerse la civilización destrozada material y simbólicamente en los campos de batalla de Europa. ${ }^{12}$

12 Navarro Trujillo, 2009: 199, señala esto especialmente en la obra de Saúl Taborda. 
Zea recupera inicialmente la pregunta de Zum Felde acerca de la personalidad americana, el interrogante acerca del "genio propio de nuestro pueblo", y junto con ella retoma la posición del filósofo uruguayo, el trance de la adolescencia, como señala respecto a la indefinición que caracteriza a Iberoamérica, pero del que ya intuye que va rumbo a la fortaleza juvenil (Zum Felde, 1943: 130). Este problema debe ser resuelto, tal como lo ve el pensador desde Montevideo, de una manera vital, no académica, y en consecuencia el asumir esa resolución no puede ser eludida por ningún americano:

Ningún americano puede evadir dicho problema, lo lleva en su sangre. Nadie puede renegar de este su ser problemático. Acaso el mal ha estado en este no resignarse a ser americano; en sentirse inferior como americano. La historia de nuestra América ofrece múltiples ejemplos de este afán de arrancarse las entrañas americanas, lo cual no ha conducido sino a esta indefinición que nos caracteriza (Zea, 1944: 127).

La reflexión de Zea luego de asumir tan enérgicamente un destino americano prosigue rechazando el "camino falso" del universalismo abstracto, ya que "El problema que nos plantea América, debe ser resuelto desde un punto de vista americano":

[...] el americano que en vez de creer o asimilar se conforme con imitar, no está en realidad sirviendo a lo universal. Lo americano, en lo que tiene de imitación de otra cultura, no puede ser lo universal (Zea, 1944: 128).

La complejidad del rechazo al universalismo cosmético, a la fácil coartada para eludir las responsabilidades de la renovación, coloca a la vez el difícil problema de la pertenencia de la cultura americana a Occidente, al que ya nos hemos referido en el comentario a Zum Felde, y que aún hoy sigue siendo una cuestión candente y polémica, en la medida en que el rechazo demagógico al eurocentrismo intenta desmantelar, junto con él, la trabajosa y ricamente tejida trama de la nueva forma de occidentalidad que se desarrolló en las Américas, vertebradora de la cultura y la sociedad, y base de la configuración cultural y política. Zea, muy tempranamente, en lo que se convertirá en una de las vías fundamentales de su programa intelectual, asume rotundamente una fórmula de Zum Felde: "Somos occidentales de América, no de Europa", que abre un inmenso territorio a la reflexión conceptual y a la investigación empírica, a través de una observación más general: la cultura occidental es una síntesis, resultado 
del "conjunto asimilado de una serie de culturas que se han venido sucediendo en Europa. Es la síntesis de todas ellas" (Zea, 1944: 129). Y acepta, como un corolario de su lectura del libro del filósofo sudamericano, y como diseño de un ancho camino abierto a su obra futura:

América, nos dice Zum Felde, puede ser el gran crisol de la nueva cultura occidental. Pero no hay que conformarse esperando que en un futuro se realice tal fusión, es nuestra inciativa, provocarla. En esta nueva síntesis cultural, las dos Américas, la sajona y la ibera tienen mucho que aportar (Zea, 1944: 130).

\section{BiBLIOGRAFÍA}

S./A. (1997); "De revistas. La pluma de Zum Felde". El País cultural, Año VIII, $1^{\circ}$ de agosto, Montevideo.

ARDAO, Arturo (1956); La filosofía en el Uruguay en el siglo xx. México: Fondo de Cultura Económica.

CRESPO, Horacio (1994); “Ezequiel Martínez Estrada. El francotirador anacrónico". La ciudad futura, Vol. 41, pp. 12-16, Buenos Aires.

DOMíNGUEZ, Carlos María (1997); El bastardo. Montevideo: Cal y Canto (2a ed., Alfaguara, 2006).

Exposición Bibliográfica y Documental. Alberto Zum Felde en el cincuentenario de la publicación de Proceso intelectual del Uruguay y crítica de su literatura (1980), Advertencia de Arturo Sergio Visca, Montevideo: Biblioteca Nacional.

FRANK, Waldo (1942); Ustedes y nosotros. Nuevo mensaje a Ibero-América. Buenos Aires: Losada.

KOZEL, Andrés (2008); Argentina como desilusión. Contribución a la idea del fracaso argentino (1890-1955), México: Nostromo Ediciones / Programa de Posgrado en Estudios Latinoamericanos-UnAM.

MICHELENA, Alejandro (1986); Los cafés montevideanos. Montevideo: Arca.

NAVARRO TRUJILlO, Mina Alejandra (2009); Los jóvenes de la "Córdoba libre!". Un proyecto de regeneración moral y cultural. México, Nostromo Ediciones / Programa de Posgrado en Estudios Latinoamericanos-unam.

OREGGIONI, Alfredo F., director (1987); Diccionario de literatura uruguaya. Montevideo: Arca Credisol (2 vols.).

PICKENHAYN, Jorge Oscar (1980); "Alberto Zum Felde y la literatura uruguaya", en Suplemento Dominical de "El Día", Montevideo, 20 de julio.

RAMA, Ángel, "Prólogo" (1967); en Roberto de las Carreras, Psalmo a Venus Cavalieri y otras prosas. Montevideo: Arca. 
REAL DE AZÚA, Carlos (1964); Antología del ensayo uruguayo contemporáneo. Montevideo: Departamento de Publicaciones de la Universidad de la República.

RODRÍGUEZ MONEGAL, Emir (1966); Literatura uruguaya del medio siglo. Montevideo: Alfa.

ROXLO, Carlos (1916); Historia crítica de la literatura uruguaya, vol. VII. Montevideo: Librería Nacional, A. Barreiro y Ramos.

RUFFINELLI, Jorge (1974); “Roberto de las Carreras. El dandy que encendió la aldea", revista Crisis, 14, Junio, Buenos Aires.

UNIVERSITY OF DELAWARE, Library, Special Collections Department, Waldo Frank Papers 1922-1965, Serie II, Writings by Waldo Frank, folders 20-23. http://www.lib.udel.edu/ud/spec/findaids/frank.htm.

VISCA, Arturo Sergio (1969); Conversando con Zum Felde. Montevideo: Biblioteca Nacional, "Reportajes culturales", nº 1 .

VISCA, Arturo Sergio (1971); "Prólogo", en Antología de poetas modernistas menores, Selección y prólogo de Arturo Sergio Visca. Montevideo: Biblioteca Artigas, Colección de Clásicos Uruguayos, vol. 139, Ministerio de Educación y Cultura.

ZEA, Leopoldo (1944); “América como problema”, en Cuadernos Americanos, Año III, 6, Noviembre-Diciembre, México.

ZUM FELDE, Alberto (1908); “Lulú Margat. Juguete trágico en un acto”, en Apolo, 16, Montevideo.

ZUM FELDE, Alberto [Aurelio del Hebrón] (1910); “El sepelio de Julio Herrera y Reissig” La Semana, Año II, No. 36, marzo 26, Montevideo.

ZUM FELDE, Alberto (1917); El Huanakauri. Montevideo: Maximino García Editor, 95 pp.

ZUM FELDE, Alberto (1919); Proceso histórico del Uruguay. Montevideo: Maximino García Editor.

ZUM FELDE, Alberto (1967); Proceso intelectual del Uruguay. Crítica de su literatura, vol. II. Montevideo: Ediciones del Nuevo Mundo, $3^{\text {a }}$ ed., p. 216 [ $1^{\text {a }}$ ed. 1930].

ZUM FELDE, Alberto (1943); El problema de la cultura americana. Buenos Aires: Editorial Losada. 